JPdK Volume 3 Nomor 1 Tahun 2021 Halaman 101-109

JURNAL PENDIDIKAN dan KONSELING

Research \& Learning in Faculty of Education

\title{
Analisis Perkembangan Ilmu Pengetahuan dan Teknologi (Iptek) Dalam Pendidikan
}

\author{
Fitri Mulyani ${ }^{1}$, Nur Haliza ${ }^{2}$ \\ Prodi Pendidikan Bahasa Inggris \\ Fakultas Ilmu Pendidikan \\ Universitas Pahlwan Tuanku Tambusai \\ Email: fitri.mulyani830@ gmail.com ${ }^{1}$, nurhaliz42710@ gmail.com ${ }^{2}$
}

\begin{abstract}
Abstrak
Penelitian ini bertujuan untuk mengetahui memaparkan Perkembangan Ilmu Pengetahuan dan Teknologi dalam pendidikan. Didalam bidang Pendidikan Teknologi memberikan proses belajar yang mudah dilakukan. Semenjak berkembangnya IPTEK proses pendidikan menjadi lebih maju. Banyak yang berubah dari waktu ke waktu karna adanya teknologi. Perubahan yaitu seperti; cara guru mengajar, cara siswa belajar dan materi pembelajaran yang selalu di perbaharui. Biasanya proses pembelajaran dengan cara bertatap muka, namun sekarang pembelajaran dapat dilakukan dengan cara dari rumah masing-masing, seperti; aplikasi zoom, google classroom dan media lain yang dapat digunakan. Selain banyak memberikan manfaat, penyalahgunaan Teknologi juga memiliki dampak negatif seperti terjadinya plagiaritas, terancamnya kerahasiaan alat tes, mamanfaatkan teknologi untuk melihat atau mecari sesuatu yang tidak baik, dan lain-lain.
\end{abstract}

Kata Kunci: Perkembangan Iptek, Pendidikan, Teknologi

\begin{abstract}
This study aims to determine how to explain the development of science and technology in education. In the field of Technology Education provides an easy learning process. Since the development of science and technology the educational process has become more advanced. A lot has changed from time to time because of technology. Changes are like; the way the teacher teaches, the way students learn and the learning material is always updated. Usually the learning process is face-to-face, but now learning can be done by means of each house, such as; Zoom, Google Classroom and other media applications that can be used. In addition to providing many benefits, misuse of technology also has negative impacts such as plagiarism, threatening the confidentiality of test kits, using technology to see or look for something that is not good, and so on.
\end{abstract}

Keywords: Science and Technology Development, Education, Technology

\section{PENDAHULUAN}

IPTEK adalah singkatan dari Ilmu Pengetahuan dan Teknologi. Seiring dengan perkembangan zaman, ilmu pengetahuan dan teknologi semakin canggih dan mendukung terciptanya teknologi-teknologi baru. Kemajuan teknologi telah mempengaruhi kehidupan ini dan tidak bisa dihindari, karena IPTEK memberikan banyak manfaat dan memudahkan pekerjaan, sebagaimana Abraham (1991: 207-209) megungkapkan bahwa proses kemajuan tektonologi menghasilkan modernitas, ditandai dengan pertumbuhan ekonomi, mobilitas sosial, ekspansi atau peluasan budaya. Pentingnya teknologi dikemukakan pula oleh Marx dan Angels (dalam budiman, 1993:43 Atmaja \& Ariani, 2018:76) bahwa melalui kemajuan Teknologi komunikasi makin canggih dan murah, berkembangnya teknologi komunikasi dapat terjadinya hubungan antara negara maju dan negara terbelakang yang teknik produksinya yang masih rendah sehingga tidak bisa dihindari. 
\begin{tabular}{lcrr}
\multicolumn{2}{c}{ Perkembangan } & IPTEK & sekarang, \\
masyarakat & dituntut & untuk & lebih \\
meningkatkan & kemampuan & dan
\end{tabular} kompetensinya, sehingga manusia dapat menyeimbangkan dirinya di zaman modern ini. IPTEK adalah awal dari kesuksesan bangsa, karena bisa menciptakan sesuatu hal yang baru yang sebelumnya tidak bisa terjadi dapat terjadi. Hal tersebut dinyatakan oleh Prof. Agus pada tahun dalam pidato presiden Soekarno di Malang pada tahun 1958 bahwa "bangsa ini akan maju dan sejahtera jika pembangunannya dilandaskan pada ilmu pengetahuan dan teknologi". Dari pendapat ini kita bisa mengetahuai bahwa tanpa adanya teknologi dan pendidikan maka tidak akan pernah ada yang namanya kemajuan.

Ilmu Pengetahuan dan Teknologi (IPTEK) sudah sangat pesat diberbagai bidang, salah satunya di dalam dunia pendidikan. Segala bentuk proses Pembelajaran dapat dilakukan dengan mudah. Tondeur et al (dalam Selwyn, 2011) menyatakan bahwa teknologi digital sekarang sudah mulai digunakan didalam bidang pendidikan sebagai sarana untuk mendukung pembelajaran, baik sebagai alat informasi (sarana mengakses informasi) atau sebagai sarana pembelajaran (penunjang kegiatan belajar dan tugas). Perkembangan IPTEK yang sangat pesat ini memunculkan peralatan dan aplikasi yang sangat mudah dipelajari dan dimanfaatkan menjadi media pembelajaran. Hal ini dinyatakan (Ratminingsih, 2020: 1) bahwa dalam berkembangnya teknologi didalam dunia pendidikan sekarang, pendidik maupun peserta didik dapat mencari dan menemukan berbagai informasi mengenai pengetahuan dengan cepat melalui jaringan internet.

Semenjak berkembangnya IPTEK bangsa telah banyak menciptakan generasi penerus yang bermutu dan berkualitas, dengan demikian penggunaan teknologi untuk pendidikan dan latihan harus dengan kreatif dan bijak. Dengan adanya perkembangan Ilmu pengetahuan dan teknologi di dalam dunia pendidikan, maka sekarang sudah menjamin adanya sistem Belajar Jarak Jauh atau dengan menggunakan media internet yang bisa menghubungkan antara pendidik (guru) dengan peserta didik(siswa) secara online Menurut H. Hamzah B. Uno dan Hj. Nina Lamatenggo, $(2011,61)$ mengatakan bahwa kecendrungan pendidikan di Indonesia dimasa mendatang adalah sebagai berikut:

1. Berkembangnya pendidikan terbuka dengan modus Belajar Jarak Jauh (Distance Learning). Kemudian untuk menyelenggarakannya perlu dimasukkan sebagai stategi pertama.

2. Kedua, dalam sebuah jaringan Sharing Resorce, perpustakaan dan instrumen pendidikan (guru, laboratorium) tidak hanya sebagai rak buku, tetapi sudah berubah menjadi sumber informasi.

3. Ketiga, perangkat teknologi informasi (CD-ROM Multimedia) dalam bidang pendidikan secara bertahap sudah berubah dengan televisi dan radio.

Pendapat yang di kemukakan oleh $\mathrm{H}$. Hamzah B. Uno dan $\mathrm{Hj}$. Nina Lamatenggo $(2011,61)$ pasa masa sekarang ini memang sudah terjadi dan bekembang dengan begitu pesat.

\section{METODOLOGI PENELITIAN}

Jenis penelitian yang dilakukan adalah penelitian studi Literatur. Menurut (Zed, 2008: 3). Studi literatur adalah rangkaian kegiatan yang mengumpulkan data pustaka, membaca, mencatat, mengolah dan menganalisis bahan penelitian. Populasi penelitian ini menelaah 7 buah jurnal dan 8 Web Site tentang Perkembangan Ilmu Pengetahuan dan Teknologi. Penelitian ini adalah artikel yang terbit pada jural penelitian yang terpublikasi secara online tahun terbitan dari dahun 2013-2020. Hasil nelaah dari berbagai artikel dengan menggunakan metode literatur ini bisa menganalisis teknologi apa saja yang digunakan dalam pendidikan serta dampak yang timbul dari berkembangnya Ilmu Pengetahuan dan Teknologi (IPTEK) dalam bidang Pendidikan. 


\section{HASIL PENELITIAN \\ DAN PEMBAHASAN}

IPTEK adalah singkatan dari ilmu pengetahuan dan teknologi. Seseorang dapat meningkatkan wawasan dan pengetahuan dibidang teknologi dengan mendapatkan informasi melalui IPTEK. Menurut Horton B, dan Chester L, H Ilmu Pengetahuan merupakan suatu saha untuk mencari pengetahuan yang masuk akal dan diandalkan serta bisa diuji secara sistematis menurut tahap-tahap yang teratur dan berdaarkan prinsip-prinsip serta prosedur tertentu. Sedangkan teknologi adalah sarana yang menyediakan kebutuhan untuk kelansungan hidup manusia. Seperti pendapat prayitno dalam Ilyyas (2001) “ teknologi adalah seluruh perangkat ide, metode, teknik dan benda-benda material yang digunakan dalam waktu dan tempat tertentu maupun untuk memenuhi kebutuhan manusia". Pengertian teknologi sebenarnya berasal dari bahasa Prancis yaitu " La Teknique" yang artinya " semua proses yang dilaksanakan dalam upaya untuk mewujudan sesuatu secar rasional". Jaques Ellul menyatakan bahwa" teknologi merupakan metode yang secara rasional mengarah dan memiliki karakteristik efisiensi dalam setiap bidang kekuatan manusia. Dalam Bidang Pendidikan ilmu pegetahuan dan teknologi dapat memberikan suatu perubahan yang lebih baik, daya saing yang tinggi sehingga menjamin memberikan kebanggan terhadapa Negeri tercinta secara kompeten.

Pendidikan adalah suatu proses untuk mendapatkan pengetahuan, keterampilan, dan kebiasaan yang dilakukan oleh sekelompok orang atau individu yang diturunkan dari satu generasi kegenerasi berikutnya melalui pengajaran pelatihan atau penelitian pendidikan. Menurut M.J. Langevel, pendidikan merupakan usaha untuk membimbing manusia yang lebih baik dari dewasa hingga kedewasaan. Pendidikan juga dikatakan sebagai suatu usaha dalam menolong anak dalam agar mandiri dan bertanggung jawab serta susila dalam kehidupannnya dimasa yang akan datang. Dalam proses pendidikan inilah mansia memperoleh ilmu pengetahuan yang sebelumnya tidak diketahui hingga menjadi tahu, denga pendidikan manusia dapat menentukan hidup yang harus ditempuh. Pendidikan dapat menjadi kunci kehidupan bagi manusia.

Semenjak berkembang IPTEK didalam dunia pendidikan proses pendidikan menjadi lebih maju. Banyak yang berubah dari waktu ke waktu karna adanya teknologi. Perubahan yaitu seperti; cara guru mengajar, cara siswa belajar dan materi pembelajaran yang selalu di perbaharui. Biasanya proses pembelajaran dengan cara bertatap muka, namun sekarang pembelajaran dapat dilakukan dengan cara dari rumah masing-masing, seperti; aplikasi zoom, google classroom dan masih banyak lagi media lain yang dapat digunakan.

Dari teknologi informasi ini banyak manfaat yang akan diperoleh, seperti pendapat Abdulhak (2005: 4130) "terdapat klasifikasi pemanfaatan ICT ke dalam tiga jenis yaitu: pertama, sebagai media atau alat bantu pendidikan yaitu hanya sebagai pelengkap untuk memperjelas uraianuraian yang disampaikan. Kedua, sebagai sumber yakni sebagai sumber informasi dan mencari informasi. Ketiga, sebagai sistempembelajaran".

Dengan adanya perkembangan zaman membawa manusia dari awalnya hanya menggunakan kertas dan pulpen untuk berkomunikasi jarak jauh antau siswa dan guru, sekarang hanya menggunakan telepon pintar untuk melampaui batas ruang dan waktu dalam waktu sekejap. Bahkan di era revolusi 4.0 yang merupakan era dimana kemajuan dari perkembangan teknologi sangat mendominasi. Era ini adalah era yang menghasilkan modernitas, sebagimana Abraham (1991 : 207-209) mengungkapkan bahwa " proses kemajuan tersebut menghasilkan modernitas, ditsandai dengan pertumbuhan ekonomi, mobilitas sosial, ekspansi atau peluasan wilayaah".

Menghadapi abad ke-21 UNESCO melailui " The Internatinal Commisiaon On Educatin For The Twenty First Century" merekomendasikan pendidikan yang berkelanjutan (seumur hidup) yang dilaksanakan berdasarkan empat pilar proses pembelajaran, yaitu: learning to know ( belajar untuk menguasai pengetahuan), learning to do ( belajar untuk 
mengetahui keterampilan), learning to be develop themselves (belajar untuk mengembangkan diri), dan learning to live together (belajar untuk hidup bermasyarakat). Dalam mencapai empat pilar pendidikan dalam era globalisasi sekarang, para guru harus memiliki kemampuan untuk muguasai dan menerapkan Teknologi Informasi dan Komunikasi dalam pembelajaran.

Menurut Rosemberg (2001), dengan berkembangnya penggunaan TIK ada beberapa pergeseran dalam proses pembelajaran yaitu: Pertama, "dari ruang kelas ke dimana dan kapan saja" maksudnya, pembelajaran yang biasa hanya dilakukan disekolah sekarang dapat dilakukan dimana saja dan kapan saja dengan melalui jaringan internet, yang mana biasanya dilakukan dengan menggunakan media google classroom, zoom dan masih banyak media yang lainnya. Kedua "dari kertas ke online atau saluran" maksudnya, biasanya siswa atau guru biasanya belajar melalui kertas atau buku, namun sekarang bisa belajar melalui berbagai media seperti google, dan menulis menggunakan word. Ketiga"dari fasilitas fisik ke fasilitas jaringan kerja" maksudnya, pembelajaran yang biasanya digunakan dengan menggunakan papan tulis hitam ataupun papan tulis putih sekarang dapat diganti ke papan tulis virtual menggunakan LCD atau layar semacam tv yang ukurannya sama dengan papan tulis".

Di dalam proses pendidikan ada beberapa teknologi yang dapat digunakan yang disebut dengan Media Teknologi Pembelajaran. Media berasal dari kata "medius" yang berarti tengah, pengantar atau perantara. Menurut Arsyad (2006: 3) dalam Bahasa Arab media yaitu "wasail atau wasilah" yang berarti perantara atau pengantar dari pengirim ke penerima pesan. Kemudian Menurut (Briggs, 1970 dalam Sadiman 2008: 6) media adalah suatu alat fisik yang dapat mendorong siswa untuk belajar dengan menyajikan pesan melalui media. Selanjutnya menurut EAC yang dikutib oleh Rohani (1997: 2) media meruakan suatu alat yang dapat digunakan untuk menyalurkan sebuah informasi.. Dari beberapa pendapat tersebut dapat disimpulkan bahwa media adalah suatu alat pengantar pesan yang menunjang dan mengembangkan pikiran dan niat siswa dalam proses Belajar. Selain itu ditegaskan juga oleh Purnamawati dan Edarni (2001: 4) mediapembelajaran adalah suatu alat yang dapat mengantarkan atau menyalurkan pesan dari pengirim kepada penerima informasi yang dapat merangsang niat, perasaan, pikiran, perhatian dan minat terhadap siswa agar proses belajar menjadi lebih baik dan efektif.

Media Teknologi dalam proses Belajar banyak memberikan manfaat bagi pendidik (guru) dan peserta didik (siswa). Contohnya seorang guru yang menggunakan media teknologi dalam menjelaskan sebuah materi, siswa akan lebih mudah memahami dan niat untuk belajar sangat besar. Hal ini ditegaskan oleh Etin Solihatin (2012: 186) bahwa manfaat media dalam pembelajaran adalah memperlancar interaksi antara guru dengan siswa sehingga dalam kegiatan pembelajaran akan lebih efektif dan efesien. Kemudian menurut Zainal Aqib (2013: 51) manfaat media pembelajaran antara lain menyempurnakan dalam penyampaian materi, pembelajaran lebih jelas dan menarik, proses pembelajaran lebih interaktif, efisiensi waktu dan tenaga, serta meningkatkan kualitas hasil belajar. Selain itu media pembelajaran yang berkualitas tinggi mampu menghasilkan prestasi belajar siswa. Menurut Djamarah (1995: 136) media suatu alat yang dapat membantu proses pembelajaran dengan cara menyalurkan informasi atau pesan melalui media. Adapun media Teknologi Pembelajaran dalam Pendidikan antara lain:

1. Kelas Online (E-Learning) Media teknologi pembelajaran yang pertama adalah media kelas online atau ELearning(Elektronik Learning). Media ini dapat dilakukan dimana dan kapan saja dalam jaringan. Menurut Darin E. Hartley, 2001) E-learning adalah suatu proses pembelajaran yang menggunakan media internet, intranet, atau media dalam jaringan yang menjamin tersampainya bahan atau materi pembelajaran kepada siswa. Internet Based disebut juga proses pembelajaran dengan jarak jauh yang bisa dilakukan kapan dan dimana saja menggunakan internet. Pembelajaran jarak jauh merupakan proses pembelajaran terpisah 
antara pendidik dan peserta didik yang menggunakan jaringan dan bersumber dari internet.

Dalam kelas Online ini terdapat dua macam tentang jenis atau persepsi dasar ELearning yaitu Electronic Based dan Internet Based. Electroik based yaitu pembelajaran yang menggunakan Teknologi informasi dan komunikasi seperti melihat video, OHP, kaset, projector, film, LCD, dan lain-lain. Hal ini dikemukakan oleh Elliot Masie, Cisco and Comellia (2000) bahwa E-Learning adalah pembelajaran yang menggunakanan media Elektronik seperti Internet, intranet, satelit, tv, CD-ROM, dan lain-lain. Sedangkan menurut Generic Center (2003) E-Learning merupakan sebuah kegiatan pembelajaran yang menggunakan fasilitas melalui dukungan rangkaian elektronik (LAN dan WAN), sebagaimana dikatakan oleh Jaya Kumar C. Koran (2002) bahwa E-Learning adalah suatu proses pembelajaran yang menggunakan rangkaian elektronik (LAN, WAN, atau internet) untuk menyampaikan metri pembelajaran, interaksi atau bimbingan.

Kelas online sangatlah mendorong kolaborasi dan keterlibatan dan dapat menjadi alat motivsi bagi para siswa dan pelajar. Menurut Roenberg (2001) ELearning lebih cenerung terhadap penggunaan teknologi melalui internet yang dapat mengirimkan serangkaian solusi untuk meningkatkan pengetahuan dan keterampilan. Pembelajaran kelas online menggunakan aplikasi antara lain:

a. Moodle

Moodle adalah singkatan dari Modulr Object Oriented Dynamic Learning Environment. Moodle adalah sebuah paket perangkat lunak yang berguna untuk melakukan kursus, pelatihan, dan pendidikan berbasis internet, hal ini dikatakan oleh Kukuh 2005:13). Media ini menunjang berhasilnya proses pembelajaran, sebagaimana dikatakan oleh M. Asrofi dalam jurnal pengembangan ELearning Berbasis Moodle bahwa model pembelajaran berbasis media moodle dapat mendukung kegiatan pembelajaran, sehingga peserta didik merasa senang dalam mengikuti pembelajaran dan dapat menerima ilmu yang disampaikan oleh guru.

b. Zoom Meeting

Zoom Meeting adalah sebuah aplikasi baru yang dapat menunjang keberhasilan dalam proses pembelajaran atau bisnis. Zoom Meeting memiliki kecanggihan yang bisa menampilkan video, gambar, animasi, slide, dan lain-lain.

c. Video dan audio Pembelajaran

Media pembelajaran adalah suatu yang dapat menyalurkan dan mengantar pesan sehingga dapat merangsang pikiran, perasaan dan kemauan minat belajar yang mendorong terciptanya proses belajar antara pendidik dan peserta didik. Pada pertengahan abad-20 pemanfaatan visual dilengkapi dengan menggunakan audio, sehingga muncullah alat bantu berupa Video. Menurut Cheppy Riyana (2007) media video pembelajaran merupakan sebuah alat yang bisa memberikan dan memudahkan pemahaman terhadap materi pembelajaran melalui video dan audio yang berisi informasi dan pesan-pesan seperti konsep, teori, prosedur, struktur, dan prinsip. Selanjutnya Cheppy Riyana mengungkapkan bahwa video pembelajaran dan proses belajar harus memiliki karakteristik dan kriterianya agar dapat menghasilkan video dan udio pembelajaran yang dapat meningkatkan motivasi dan efeksivitas. Karakteristik video pembelajaran antara lain Carity of Massage (kejelasan pesan), Stand Alone(berdiri sendiri), User Friendly(akrab dengan pemakainya), representasi isi, dan visualisasi dengan media. Media video Pembelajaran juga dapat digunakan secara individual dengan menggunakan gadged dan komputer kapan dan dimana saja. Ciri video pembelajaran antara lain Carity of Massage (kejelasan pesan), Stand Alone (berdiri sendiri), User Friendly (akrab dengan pemakainya), representasi isi, dan visualisasi dengan media. Media pembelajaran video juga dapat digunakan oleh individu dengan menggunakan perangkat lunak dan komputer kapan saja.Kelebihan Media Video pembelajaran dapat memanipulasi waktu yang dibisa dilihat pada waktu luang yang mampu melatih kemampuan kegiatan. Munurut Hamzah B.Uno dan Nina Lamatenggo 
(2011: 135) kelebihan Media video pembelajaran antara lain (1) dapat memanipulasi waktu dan ruang yang bida dilakukan pada waktu luang, (2) dapat menampilkan bermacam-macam objek yang terlalu kecil hingga terlalu kecil. besar, berbahaya, atau bahkan tidak dapat dikunjungi oleh siswa, (3) kemampuan media video dapat melatih kemampuan dan keterampilan motorik.

\section{d. Google Classroom}

Google Classroom atau ruang kelas google merupakan aplikasi pembelajaran secara online. Pada tahun 2014-2016 google classroom hanya digunakan oleh sekolah yang in in google, tetapi pada bulan Maret 2017 google classroom telah digunakan dan diakses oleh semua orang secara pribadi Tujuan utama Google Classroom yaitu berbagi file antara guru dan pesert didik. Dalam penelitian yang dilakukan oleh Shampa Iftakhar (2016) yang berjudul Google Classroom: What Works and How that google classroom dapat memonitor siswa untuk belajar. Menurut Wikipedia (2017) ada beberapa fitur yang dimiliki olelh Google Classroom antara lain 1) Assingment (tugas), 2) Grading (pengukuran, 3) Communicaton (komunikasi), 4) Time Cost (peng waktu), 5) Archiev Course (arsip program), 6) Aplikasi Mobile (aplikasi dalam telepon genggam), dan 7) Privasi (privasi).

\section{Kelas Offline (tatap muka)}

Kita tahu bahwa Offline berarti proses pembelajaran yang dilakukan secara tatap muka atau langsung antara pendidik dengan peserta didik. Dalam proses pembelajaran tatap muka sekarang, pendidik tidak hanya menyampaikan materi berdasarkan buku, tetapi bisa dilakukan dengan cara mempresentasikan dengan LDC proyektor yang dibantu oleh sebuah komputer atau laptop. Hal ini dapat membuat proses belajar semakin aktif yang mendorong minat bagi siswa. Adapun Media teknologi pembelajaran yang digunakan dalam belajar tatap muka ini antara lain:

a. Proyektor LCD

Proyektor LCD adalah sebuah alat yang bisa menampilkan foto, gambar, video, audio, animasi serta slide dengan menghubungkan dengan alat elektronik seperti komputer dan laptop. Proyektor LCD ini sudah banyak dilakukan untuk bisnis dan pendidikan. Metode yang digunakan yaitu berupa presentasi. Seorang autor (pendidik) akan menyampaikan materi dengan melihatkan langsung kepada peserta didik. Dengan demikian siswa akan lebih mudah memahami apa yang disampaikan oleh guru, karena proyektor ini menampilkan gambar dengan ukuran besar. Menurut Sudjana dan Rivai (1992,2) mengatakan bahwa manfaat proyektor LCD bagi siswa sangat banyak, antara lain yaitu (a) Pembelajaran lebih menarik perhatian siswa sehingga dapat menumbuhkan motivasi belajar (b) Bahan pelajaran akan lebih jelas maknanya sehingga dapat lebih dipahami oleh siswa dan memungkinkannya menguasai dan mencapai tujuan pembelajaran (c) Metode mengajar akan lebih bervariasi (d) siswa lebih banyak melakukan kegiatan belajar sebab tidak hanya mendengarkan uraian guru.

b. Komputer.

Pembelajaran Berbasis Komputer berasal dari istilah Computer Assisted Intruction (CAI) yang berarti pembelajaran berbantuan komputer. Media ini merupakan program yang menggunakan software. Selain itu, pembelajaran berbasis komputer merupakan kegiatan belajar yang menggunakan komputer untuk membantu guru dalam menyampaikan materi pembelajaran, sehingga siswa merasa senang dan tidak bosan dalam proses pembelajaran yang sedang berlangsung. Hick dan Hyde, mengatakan bahwa dengan pembelajaran berbasis komputer berhadapan langsung dengan siswa akan berinteraksi dan komputer secara individual sehingga apa yang dialami oleh seorang siswa akan berbeda dengan apa yang dialami oleh siswa lain.. Selanjutnya Warsita mengatakan bahwa pembelajaran berbasis komputer adalah salah satu media pembelajaran yang sangat menarik dan mampu meningkatkan motivasi belajar peserta didik. Robert Heinich, Molenda, dan James D. Russel (dalam Rusman, 2013: 97), mengatakan bahwa pembelajaran komputer dapat menyampaikan pembelajaran secara individual dan 
langsung kepada para siswa dengan cara berinteraksi dengan mata pelajaran yang diprogramkan kedalam sistem komputer.

Penggunaan Komputer bagi media pembelajaran dibagi dua jenis antara lain Computer Assisted Instructional (CAI) dan Computer Aided Learning (CAL) yang dikemukakan oleh Soekartawi. CAI berfungsi sebagai penyaji, menyimpan dan menganalisis evaluasi materi pembelajaran, sedangkan CAL penggunaan komputer dalam menyampaikan materi pembelajaran dengan melibatkan peserta didik secara aktif. Bentuk Pemanfaatan multimedia berbasis komputer menurut Yudhi Munadi antara lain (1) multimedia presentasi, (2) program multimedia Interaktif, dan (3) sarana simulasi.

Komputer adalah suatu alat elektronik multifungsi yang di gunakan untuk mengolah data, mempermudah siswa dalam mengerjakan tugas dan memdapat informasi pembelajaran yang belum dipelajari disekolah. Begitu banyak dampak atau perubahan dan pengaruh yang terjadi dalam dunia pendidikan sejak perkembangan IPTEK. Kemunculan IPTEK merubah segalanya, IPTEK telah membuat segala sesuatu menjadi lebih mudah dan murah. Terkadang manusia berfikir bahwa teknologi itu adalah penghancur. Namun, itu kembali lagi kepada diri manusia karna yang menjalankan teknologi itu sendiri adalah manusia.

1. Dampak positif perkembangan IPTEK dalam pendidikan:(1)Memudahkan dalam proses mengakses informasi yang berkaitan dengan pendidikan, sesuai dengn pendapat Bambang Warsita (2008:135) “ teknologi informasi adalah sarana dan prasarana (hardware, software, useware) sistem dan metode untuk memperoleh, mengirim, mengolah, menafsirkan, menyimpan, mengogarnisasikan dan mengginakan data secara bermakna".(2)Pembaharuan dalam pembelajaran seperti e-learning dapat memudahkan dalam proses pembelajaran. (3) memudahkan guru dalam memberikan matri pembelajan mengggunakan internet. (4) Munculnya media masa yang memudaahkan untuk memperoleh ilmu atau inforormasi terbaru.(5)Munculnya metodemetode pembelajaran yang baru, yang dapat memudahkan siswa agar lebih cepat memahami pembelajaran.(6)Sistem

pembelajaran tidak hanya dengan tatap muka, tapi juga dengan menggunakan berbagai media aplikasi seperti zoom, google classroom, dll.(7)Mengurangi ketertinggalan teknologi dari negara berkembang.(8)Dapat meningkatkan kualitas sumberdaya manusia dalam mengembangkan ilmu pendidikan dan teknologi. (9)Teknologi sebagai sistem yang mendudung dalam proses pendidikan. (10)Memperoleh informasi atau pun pendapat para ahli dari segala penjuru dengan cepat.(11)Dapat membaca buku tampa harus membeli buku, yaitu hanya dengan menggunakan internet.(12)Dapat berdiskusi dengan temam melalui online. (13) pemenuhan kebutuhan akan fasilitas pendidikan dapat dipenuhi dengan cepat. (14) munculnya media massa, khususnya media elektronik sebagai sumber ilmu dan pusat pendidikan. Seperti jaringan internet, Leb. Komputer dan lainlain.

2. Dampak negatif perkembangan IPTEK dalm pendidikan: (1) Terjadinya plagiaritas (2) Jika terjadi kecerobohan dalam sebuah sistem di lembaga pendidikan mak akan berakibat fatal. (3) Semakin terancamnya kerahasiaan suatu program yang dapat diakses. (4) kesalah gunaan teknologi, seperti tindak kriminal.

Mempertimbangkan penggunaan teknologi bagi peserta didik di bawah umur.

Mempertimbangkan penggunaan teknologi untuk anak di bawah umur. (7) Membuat siswa bahkan guru kecanduan dengan menggunakan teknologi. 
Menggunakan teknologi untuk mecari sesuatu yang tidak jelas. (9) Siswa menjadi malas belajar. Dengan adanya teknologi yangg semakin canggih yang dapat mempermudah proses belajar bagi siswa terkadang membuat siswa lebih malas belajar karena sudah adanya kemudahan tersebut, bahkan dengan teknologi tersebut mereka lebiih memilih untuk bermain game ataupun sosialmedia. (10) Terjadinya pelanggaran asusila. Seperti terjadinya tauran antar pelajar, terjadinya priseks, pemerkosaan dan lainnya. (11) Terjadinya penyalahgunaan pendidikan oleh orang-orang yang tidk bertanggung jawab, yang ingin melakukan tindak kriminal. (12) Adanya pihak yang tidak bertanggung jawab dalam penyalahgunaan teknologi untuk sebuah sistem pengolah data.

\section{SIMPULAN}

IPTEK adalah singkatan dari ilmu pengetahuan dan teknologi, yaitu suatu sumber informasi yang dapat meningkatkan pengetahuan ataupun wawasan seseorang dibidang teknologi. IPTEK adalah awal dari kesuksesan bangsa, karena bisa menciptakan sesuatu hal yang baru yang sebelumnya tidak bisa terjadi dapat terjadi. Hal ini disampaikan oleh Prof. Agus tentang pidato presiden Soekarno di Malang pada tahun 1958, ia menyatakan "bahwa bangsa ini akan maju dan sejahtera jika pembangunannya dilandaskan pada ilmu pengetahuan dan teknologi". Semenjak berkembangnya penggunaan IPTEK dapat mempermudah segala hal terutama di bidang pendidikan, yang mana biasanya sekolah tatap muka namun karna adanya teknologi dapat dilakukan dari rumah. Semua itu dapat dilakukan dengan menggunakan internet melalui media seperti google classroom, zoom dan lainnya.

Terkadang manusia berfikir bahwa teknologi itu adalah penghancur. Namun, itu kembali lagi kepada diri manusia karna yang menjalankan teknologi itu sendiri adalah manusia. Dampak positif teknologi dalam pendidikan salah satunya memudahkan Proses pembelajaran dimana dan kapan saja, sedangkan dampak negatif yang timbul dalam penyalahgunaan IPTEK yaitu menggunakan teknologi untuk melalukan sesuatu yang tidak penting atau tidak berguna, dan dapat juga mengakibatkan siswa malas dalam belajar.

\section{DAFTAR PUSTAKA}

Abdulfattah, Ahsan dan Suprahar. (2016) .PENGEMBANGAN E-LEARNING BERBASIS MOODLE UNTUK MENINGKATKAN HASIL BELAJAR PESERTA DIDIK DI MAN YOGYAKARTA 1. Jurnal pendidikan fisika, $V, 351-360$.

Almanda Putra, Aulya. (2017). PENERAPAN MODEL PEMBELAJARAN JARAK JAUH KETERAMPILAN BERBASIS MEDIA GOOGLE CLASSROOM UNTUK MENULIS. Diakses pada (31 Desember 2020). Hal 19-23

Amesi, Novita dan Hamid K, Abdul. (2015, Juni). PENGGUNAAN MEDIA PEMBELAJARAN ONLINE-OFFLINE DAN KOMUNIKASI

INTERPERSONAL TERHADAP BELAJAR BAHASA INGGRIS. Jurnal Teknologi Informasi dan Komunikasi, II, 85- 99.

Blingshine. (2013, 11 September). Dampak Positif dan Negatif Teknologi Informasi dan

Komunikasi dalam Bidan Pendidikan, Pemerintah, dan Ekonomi. Diakses pada (17 Desember 2020), dari nlingjamong.wordpress.com:

https://blingjamong.wordpress.com/ 2013-11/18/1-1dampakpositif-dannegatif-teknologi-informasi-dan-

komunikasi-dalam-bidang-

pendidikan-pemerintah-dan-

ekonomi/amp/

Budiman, Haris. (Mei 2017), PERAN TEKNOLOGI

INFORMASI DAN

KOMUNIKASI DALAM

PENDIDIKAN. Jurnal Pendidikan Islam, VIII, 75-83 
Dwi Wicaksono, Vicky dan Rachmadyanti, Putri. (2017). PEMBELAJARAN BLENDED

LEARNING MELALUI GOOGLE CLASSROOM DI SEKOLAH DASAR. Jurnal Seminar Nasional Pendidikan. 513-521.

Gustri Ayu Puspa Yanti, S. (2020, 31 Agustus). Perkembangan Teknologi dalam Dunia Pendidikan Menguntungkan atau Merugikan? Diakses pada 17 Desember 2020 dari

id: https://posbali.co.id/perkembanganteknologi-dalam-pendidikan-

POSBALI.bersama. merugikanatau-menguntungkan/

Jamun, Yohannes. Marryono. (2018, 1 Januari). DAMPAK TEKNOLOGI TERHADAP PENDIDIKAN. Jurnal pendidikan dan kebudayaan Missio, 48-52.

Lestari, Sudarsri. (2018, Agustus). PERAN TEKNOLOGI PENDIDIKAN GLOBALISASI. DALAM JURNAL PENDIDIKAN AGAMA ISLAM, II, 94-100.

Mahpudin, Heri. (2917, Januari 28). CONTOH TEKNOLOGI DALAM BIDANG PENDIDIKAN.

Di akses pada (28 Desember 2020) dari Sintesanetwork. https://satujam.com/teknologipendidikan/

Michael, Elkan. (2017, April 02). PENGERTIAN MEDIA VIDEO PEMBELAJARAN

MENURUT PARA AHLI. Diakses pada (27 Desember 2020) dari meaningaccordingtoexpert.com. https://meaningaccordingtoexperts. blogspot.com/2017/04/pengertianmedia-video- pembelajaran.html-1

Novacaem. (2012, April 24). Pembelajaran Tatap Muka. Diakses pada (29 Desember 2020) dari SCRIBDhttps://id.scribd.com/doc/9 0930452/pembelajaran-tatap-muka

Syafnur, Yolanda. (2016, Maret 22). PEMBELAJARAN BERBASIS KOMPUTER. Diakses

pada (27 Desember 2020)dariYolandasyafnur.blogspot. http://yolandasyafnur.blogspot.com /2016/03/pembelajaran-b

Syahrulstkip. (2017, Maret 20). PERANAN KOMPUTER DALAM BIDANG PENDIDIKAN. Diakses pada (28 Desember 2020) dari iLearningmedia. https://ilearning.me/2017/03/20/pera nan-komputer-dalam-bidangpendidikan 